\title{
The Influence of Hydrogen on the Properties of Zinc Sulfide Thin Films Deposited by Magnetron Sputtering
}

\author{
Hang Xu, Lili Wu, Wenwu Wang, Lixiang Zhang, Jingquan Zhang, \\ Wei Li, and Lianghuan Feng
}

College of Materials Science and Engineering, Sichuan University, Chengdu 610064, China

Correspondence should be addressed to Lili Wu; wulily77@163.com

Received 7 October 2013; Accepted 16 March 2014; Published 7 April 2014

Academic Editor: Fahrettin Yakuphanoglu

Copyright (c) 2014 Hang Xu et al. This is an open access article distributed under the Creative Commons Attribution License, which permits unrestricted use, distribution, and reproduction in any medium, provided the original work is properly cited.

\begin{abstract}
Zinc sulfide thin films have been deposited with hydrogen in $\mathrm{Ar}$ and $\mathrm{Ar}+\mathrm{H}_{2}$ atmosphere by radio frequency magnetron sputtering. The thickness, structural properties, composition, surface morphology, and optical and electrical properties of the films have been investigated. Effect of hydrogen on the properties of the film was studied. The results showed that hydrogen leads to better crystallinity and larger crystallite size of $\mathrm{ZnS}$ polycrystalline films. The band gaps of the films in $\mathrm{Ar}+\mathrm{H}_{2}$ are about $3.48 \mathrm{eV}$ compared with $3.24 \mathrm{eV}$ without hydrogen. It is also demonstrated that hydrogen can result in a better stoichiometric composition of the films.
\end{abstract}

\section{Introduction}

Zinc sulfide $(\mathrm{ZnS})$ thin films have been widely used in optoelectronic device application including optical switching device, photo catalysts, and optical sensors because of their outstanding properties such as wide band gap $(3.65 \mathrm{eV})$, high refractive index (2.35), and high dielectric constant [1]. Cadmium sulfide (CdS) thin films have been extensively studied for their proven applications in optoelectronic devices [2] and as a window layer in heterojunction solar cells based on cadmium telluride (CdTe) owing to their wide band gap $\left(E_{g}=2.42 \mathrm{eV}\right)$ and are easy to be prepared by lowcost methods [3]. Compared to CdS thin films, ZnS thin films have much higher band gap. The wide band gap is not only conducive to open circuit voltage of solar cells but also good for the film with higher film thickness as window layer to reduce lattice defects. In addition, $\mathrm{ZnS}$ thin films are cadmium free. So we do not have to worry about the serious environmental problems due to the large amount of $\mathrm{Cd}$ compound wastes during the deposition process. Thus, $\mathrm{ZnS}$ thin film has been considered as a promising material used as an alternative buffer layer instead of CdS film in CdTe based solar cells. Currently, ZnS buffer layers have been prepared by several methods, such as sputtering [4], chemical vapor deposition [5], chemical bath deposition (CBD) [6, 7], electrodeposition [8], and pulsed-laser deposition [9]. Among these methods, magnetron sputtering is still a relatively costeffective deposition technique compared with those listed above and has sufficient control over the deposition rate and uniformity of the films.

A few works have been published to date, which specially studied the properties of $\mathrm{ZnS}$ thin films deposited by RF magnetron sputtering. Hwang's group [10] investigated the influence of different substrate temperatures on the structural and optical properties of $\mathrm{ZnS}$ thin films. The results showed that the $\mathrm{ZnS}$ films grown at $350^{\circ} \mathrm{C}$ exhibit a relatively high transmittance of $80 \%$ in the visible region and a strongly (111) preferred orientation with better crystallinity. However, it is not easy to maintain the uniformity of the substrate temperature when this method is applied to the manufacture of large area modules. Room temperature deposition process will be more suitable if the properties of films are satisfied. It is reported that hydrogen was commonly used as auxiliary gas in the preparation of alloy membranes, optical and semiconductor films by magnetron sputtering [11-15]. Wang's group [16] studied the influence of $\mathrm{H}_{2} / \mathrm{Ar}$ ratio on the structural, electrical, and optical properties of hydrogen and tungsten codoped $\mathrm{ZnO}$ films deposited by pulsed magnetron sputtering. The research showed that hydrogen has a positive effect on the improvement of the microstructure of $\mathrm{ZnO}$ films. The above reports suggest that hydrogen may play an 
important role in magnetron sputtering and more studies of $\mathrm{ZnS}$ thin films deposited in atmosphere with hydrogen by RF magnetron sputtering are needed. In this paper, $\mathrm{ZnS}$ films were deposited at room temperature in Ar atmosphere mixed with different hydrogen flux. The effects of hydrogen on the characteristics of $\mathrm{ZnS}$ thin films were reported and the working mechanism of hydrogen during the sputtering process was studied theoretically.

\section{Experimental}

2.1. Preparation Process. ZnS films were deposited at silica glass substrates by RF magnetron sputtering. The substrates experienced cleanser, acetone, anhydrous ethyl alcohol, and ultrasonic cleaning for about 10 minutes each and were rinsed with deionized water before drying. After cleaning, the substrates were immediately preserved in a drying cabinet. Before deposition, substrates were loaded onto the sample holder about $100 \mathrm{~mm}$ away from a $\mathrm{ZnS}$ target (99.999\%) in the vacuum chamber. The chamber was pumped down to a base pressure of $1 \times 10^{-3} \mathrm{~Pa}$. Argon or argon mixed with a small amount of hydrogen was used as the sputtering gas.

In order to clean the surface of the target and ensure a stable sputtering process, presputtering for several minutes was performed with an RF power of $350 \mathrm{~W}$ while the substrate was covered with a shield. During the deposition process, the working pressure was maintained at $0.5 \mathrm{~Pa}$ or $0.2 \mathrm{~Pa}$. The deposition time was 30 minutes and the sputtering power was maintained at $300 \mathrm{~W}$. The substrates were maintained at the room temperature.

2.2. Characterization Methods. The surface morphology of the films was determined by Scanning Electron Microscope (SEM) (Hitachi-S4800, Japan). The composition of the films on glass substrates was investigated by Inductively Coupled Plasma Optical Emission Spectrometer (ICP-OES) (Spectro ACROS, Germany). The film thickness was measured with a profile system (Ambios XP-2, America). The physical structure and grain size of the films were studied with an X-ray diffractometer (XRD) (Dandong Fangyuan DX-260, China). The electrical property of $\mathrm{ZnS}$ films was tested by thermal probe test system. The optical properties of the films were characterized by an UV-Visible spectrophotometer (Perkin Elmer Lambda950, America) with a wavelength range from $200 \mathrm{~nm}$ to $2500 \mathrm{~nm}$.

\section{Results and Discussion}

\subsection{Thickness and Structure Analysis}

3.1.1. Thickness of ZnS Film. In order to better understand the results or discussion, the samples were named after the sputtering pressure and hydrogen partial pressure ratios that are listed in Table 1. The film thickness is shown in Figure 1. From Figure 1 we can see that the samples deposited at $0.2 \mathrm{~Pa}$ are thicker than those grown at $0.5 \mathrm{~Pa}$. It is easy to understand because higher sputtering pressure means higher density of

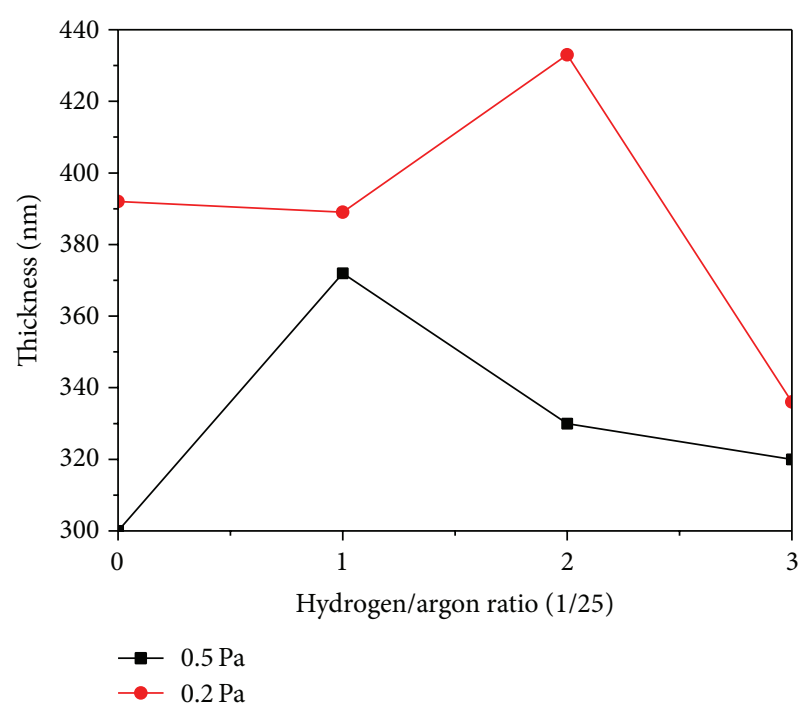

FIgURE 1: Thickness of the $\mathrm{ZnS}$ thin films deposited at varied sputtering atmosphere.

gas molecules, which would enhance the probability of colliding which occurred between gas molecules and sputtering particles. The colliding decreases the deposition rate of $\mathrm{ZnS}$ films by changing the direction of sputtering particles away from the substrates. With the increase of hydrogen, the film thickness increased at first and then decreased.

It means that the amount of hydrogen had an impact on the deposition process of the films.

3.1.2. Structural Properties. X-ray diffraction patterns of the ZnS films prepared in different sputtering atmosphere are shown in Figure 2. Figure 2 shows that all the $\mathrm{ZnS}$ films are wurtzite polycrystalline structure with a preferential orientation in (100) direction.

Figure 3 gives the average crystallite size $(D)$ of different $\mathrm{ZnS}$ films, which is calculated using Scherrer formula:

$$
D=\frac{K \lambda}{\beta \cos \theta},
$$

where $\lambda$ is the $\mathrm{X}$-ray wavelength $(1.5405 \mathrm{~nm}), \beta$ is the full width at half maximum (FWHM) of the film diffraction peak in (100) direction, and $\theta$ is the Bragg diffraction angle.

It is observed that the $D$ values of the films deposited at $0.2 \mathrm{~Pa}$ were larger than those at $0.5 \mathrm{~Pa}$ except for $3 / 25$ $\mathrm{H}_{2} / \mathrm{Ar}$ ratio. From Figure 3, we can see that the average grain size of the films increased at first and then decreased with the increase of hydrogen. This result is consistent with the SEM analysis (Figures 5 and 6). This means that lower sputtering pressure leads to larger crystal size and the increase of hydrogen partial pressure results in a larger crystal size except the sample with much hydrogen.

3.2. Composition. The ICP-OES measurements were done to determine the composition of $\mathrm{ZnS}$ films. Figure 4 shows the influence of $\mathrm{H}_{2} / \mathrm{Ar}$ ratio on film compositions. All 
TABLE 1: Sample names of $\mathrm{ZnS}$ thin films deposited in different sputtering atmosphere.

\begin{tabular}{lcccccccc}
\hline & \multicolumn{3}{c}{0} & \multicolumn{3}{c}{ Pressure } \\
& \multicolumn{2}{c}{$0.5 \mathrm{~Pa}$} & & \multicolumn{3}{c}{$0.2 \mathrm{~Pa}$} \\
\hline Ar/ $\mathrm{H}_{2}$ ratio & $25: 0$ & $25: 1$ & $25: 2$ & $25: 3$ & $25: 0$ & $25: 1$ & $25: 2$ \\
Sample name & $0.5 \mathrm{P}-\mathrm{Ar}$ & $0.5 \mathrm{P}-\mathrm{H}$ & $0.5 \mathrm{P}-2 \mathrm{H}$ & $0.5 \mathrm{P}-3 \mathrm{H}$ & $0.2 \mathrm{P}-\mathrm{Ar}$ & $0.2 \mathrm{P}-\mathrm{H}$ & $0.2 \mathrm{P}-2 \mathrm{H}$ & $0.2 \mathrm{P}-3 \mathrm{H}$ \\
\hline
\end{tabular}

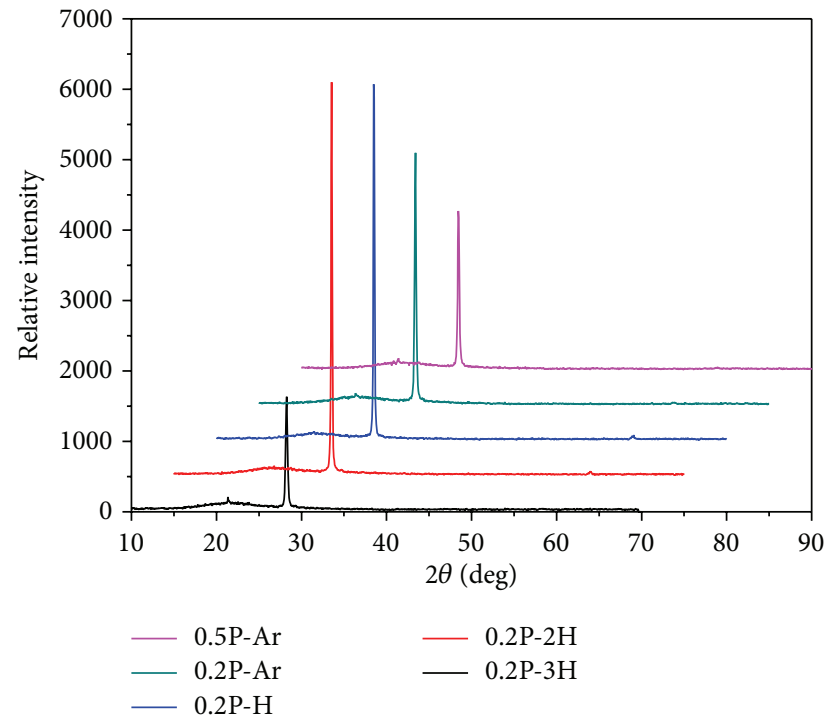

FIGURE 2: XRD patterns of $\mathrm{ZnS}$ films grown at various atmospheres.

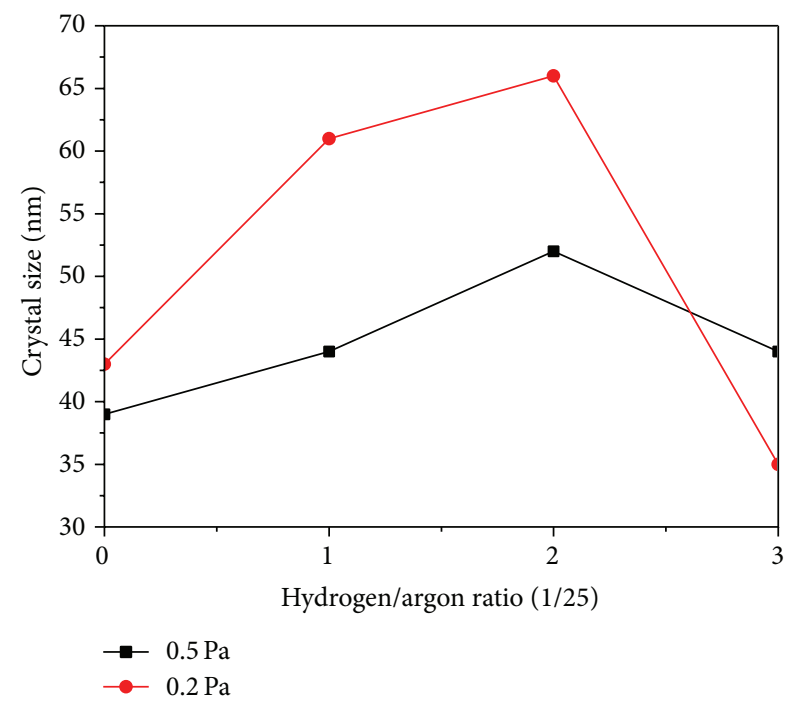

Figure 3: Crystal size $(D)$ of the $\mathrm{ZnS}$ thin films.

samples prepared in various sputtering atmospheres were nonstoichiometric, and $\mathrm{Zn}$ had more content than $\mathrm{S}$. The $\mathrm{Zn} / \mathrm{S}$ ratio decreased obviously as the $\mathrm{H}_{2} / \mathrm{Ar}$ ratios were elevated. Figure 4 also shows that the $\mathrm{Zn} / \mathrm{S}$ ratios of the films at $0.2 \mathrm{~Pa}$ were closer to $1: 1$ compared to the samples at $0.5 \mathrm{~Pa}$ except the one with $2 / 25 \mathrm{H}_{2}$ /Ar ratio.

It means that lower sputtering pressure results in a better stoichiometry and the introduction of hydrogen leads to

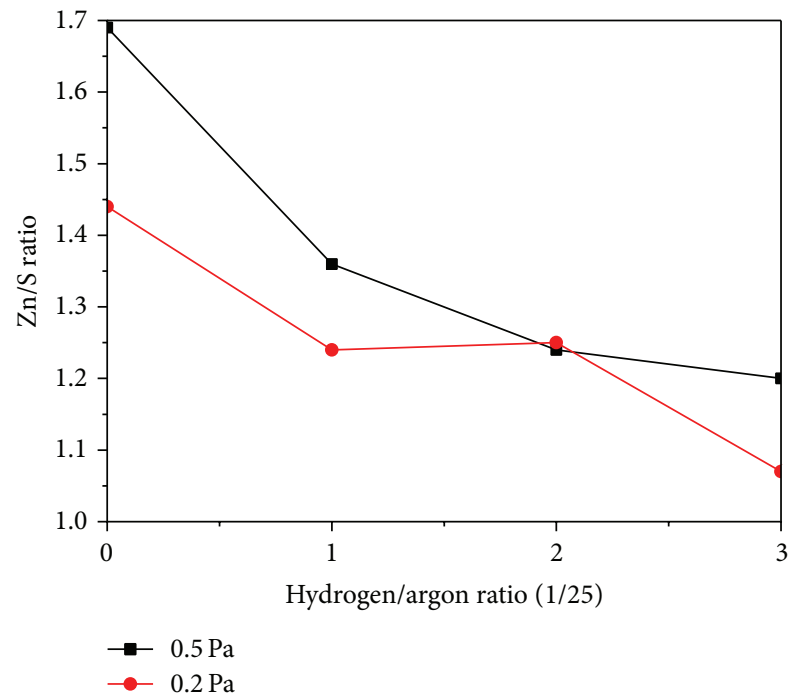

FIGURE 4: $\mathrm{Zn} / \mathrm{S}$ ratio of $\mathrm{ZnS}$ films deposited in various atmospheres.

a near stoichiometry of $\mathrm{Zn} / \mathrm{S}$ ratio. But the upper limit of $\mathrm{H}_{2}$ /Ar ratio was chosen to be $3: 25$ because higher content of hydrogen decreases the grain size of $\mathrm{ZnS}$ films (Figure 6(d)) and may cause hydrogen doping [17] although it leads to stoichiometric composition of films.

It is difficult to have a good understanding of the mechanism how hydrogen leads to a better $\mathrm{Zn} / \mathrm{S}$ ratio. But we try to understand it as follows. Zinc oxide film was obtained only or cannot be avoided until the well optimization of sputtering conditions during the $\mathrm{ZnS}$ deposition. The sputtering particles bombarded out from ZnS target by argon ions, such as $\mathrm{Zn}^{2+}, \mathrm{S}^{2-}, \mathrm{ZnS}$, and molecular clusters, would present strong oxidability or reducibility caused by the small size effect. On the other hand, it is difficult to keep all the oxygen away from the vacuum chamber. Even a small amount of oxygen can result in the redox reaction and the growth of zinc oxide film on the substrate instead of $\mathrm{ZnS}$ film. Thus, hydrogen was introduced to prevent the sputtering particles from oxidation by maintaining a reducing protective atmosphere. This idea was supported because a small amount of hydrogen sulfide was smelled when the vacuum chamber was just open after deposition and there was some yellow elemental sulfide found at the surface of $\mathrm{ZnS}$ target. These results demonstrated that hydrogen indeed had the effect of reduction during the magnetron sputtering process.

3.3. Surface Morphology. Figures 5 and 6 show the surface morphology of the ZnS films scanned by SEM. Figure 5 shows the morphology of the films deposited at $0.5 \mathrm{~Pa}$ with different 


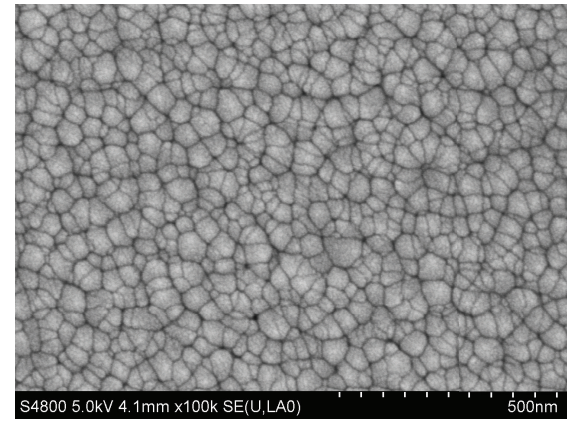

(a)

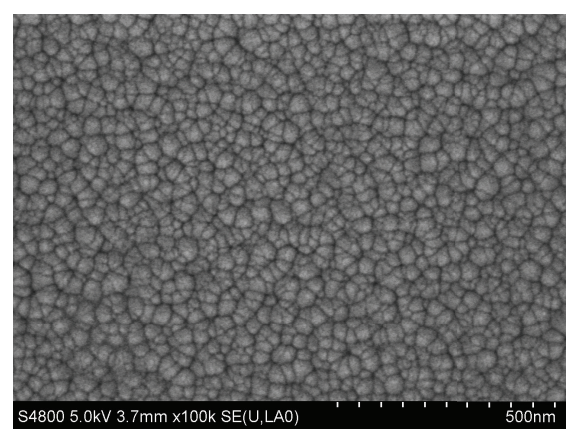

(c)

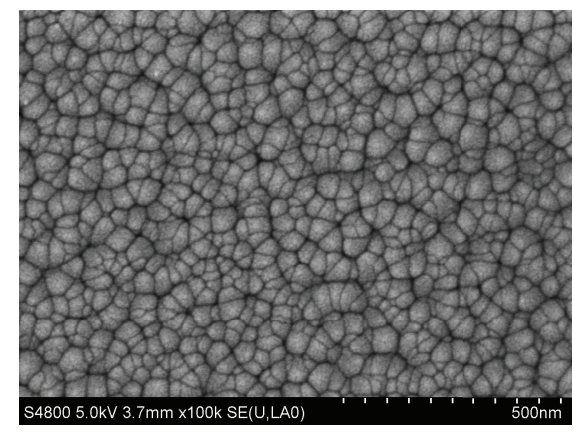

(b)

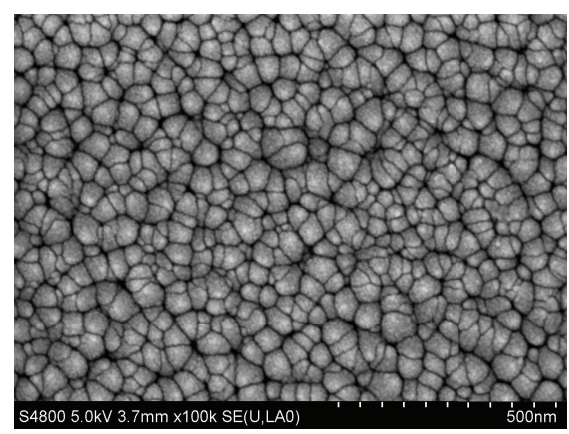

(d)

FIGURE 5: SEM images of ZnS films grown in various atmospheres. (a) 0.5P-Ar, (b) 0.5P-H, (c) 0.5P-2H, and (d) $0.5 \mathrm{P}-3 \mathrm{H}$.

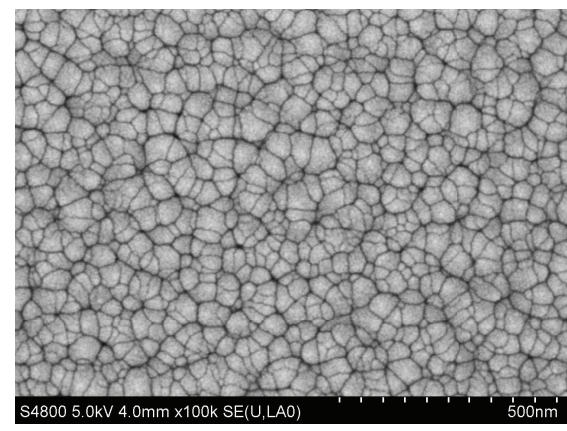

(a)

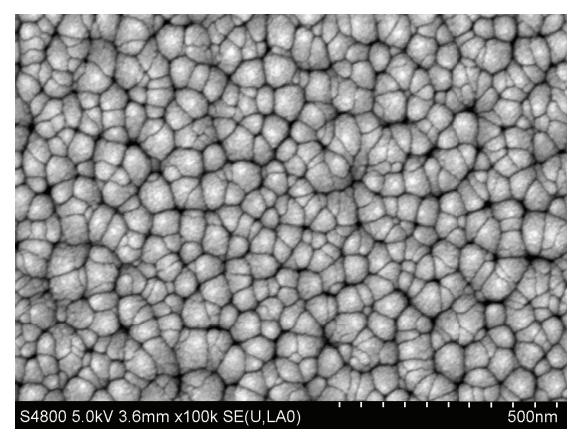

(c)

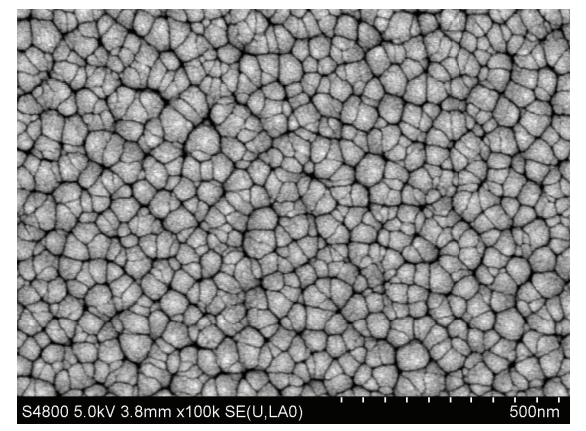

(b)

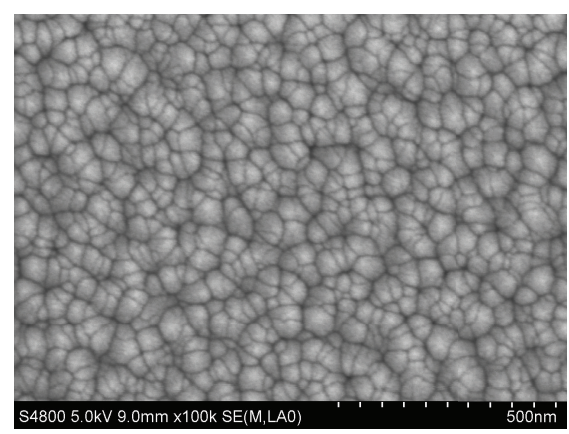

(d)

FIGURE 6: SEM images of $\mathrm{ZnS}$ films grown in various atmospheres. (a) 0.2P-Ar, (b) $0.2 \mathrm{P}-\mathrm{H}$, (c) $0.2 \mathrm{P}-2 \mathrm{H}$, and (d) $0.2 \mathrm{P}-3 \mathrm{H}$. 


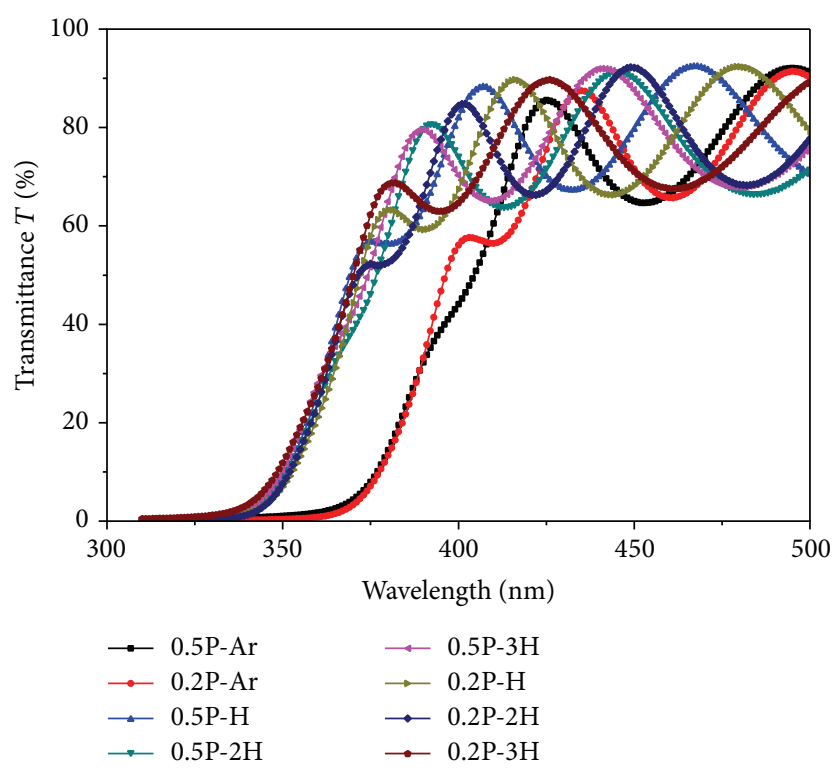

FIGURE 7: Transmittance versus wavelength spectra of ZnS films grown at various sputtering pressures.

$\mathrm{H}_{2} / \mathrm{Ar}$ ratio. Figure 6 shows the morphology of the films deposited at $0.2 \mathrm{~Pa}$ with different $\mathrm{H}_{2}$ /Ar ratio. In general, the surface of the $\mathrm{ZnS}$ films is smooth and compact with uniform particles.

From Figures 5 and 6, we know that the surface morphology of $\mathrm{ZnS}$ films deposited at different atmospheres has no obvious difference except the particle sizes. The change of grain size in SEM images is small and not easy to find out while it can be clearly differentiated by crystal size calculated from XRD peak. In Figure 6, the SEM images of $0.2 \mathrm{P}-\mathrm{H}$ and $0.2 \mathrm{P}-2 \mathrm{H}$ show the larger grain size and clear grain boundary while the images of $0.2 \mathrm{P}-\mathrm{Ar}$ and $0.2 \mathrm{P}-3 \mathrm{H}$ show the small crystal size, corresponding to the variation of crystal size in Figure 3.

These images indicate that $\mathrm{ZnS}$ films deposited at $0.2 \mathrm{~Pa}$ have better crystallinity and hydrogen can promote the crystal size of the film to some extent. This may be explained by the dynamic equilibrium between surface enhanced diffusion and selective etching effect of hydrogen. There is a plasma area produced by the RF power during the process of RF magnetron sputtering. In the plasma area, there are some important reactions [18]:

$$
\mathrm{H}_{2}{ }^{* *}+\mathrm{H}_{2}{ }^{*} \longrightarrow \mathrm{H}_{2}{ }^{+}+\mathrm{H}_{2}+\mathrm{e}
$$

which shows the excitation transfer and radioactive decay process of excited hydrogen:

$$
\begin{aligned}
& \mathrm{H}_{2}^{+}+\mathrm{H}_{2} \longrightarrow \mathrm{H}_{3}^{+}+\mathrm{H} \\
& \mathrm{Ar}^{+}+\mathrm{H}_{2} \longrightarrow \mathrm{ArH}^{+}+\mathrm{H}
\end{aligned}
$$

which shows the generation process of $\mathrm{ArH}^{+}, \mathrm{H}_{3}{ }^{+}$, and hydrogen radical $(\mathrm{H})$.

Hydrogen radical leads to surface diffusion effect [19-21] and selective etching effect $[21,22]$ in a-Si:H, $\mu \mathrm{c}-\mathrm{Si}: \mathrm{H}$, or c$\mathrm{Si}: \mathrm{H}$ deposition. Surface diffusion effect is conducive to grain
TABLE 2: The optical band gaps of the films deposited in various sputtering atmospheres.

\begin{tabular}{lc}
\hline Sample name & Band gap $(\mathrm{eV})$ \\
\hline $0.5 \mathrm{P}-\mathrm{Ar}$ & 3.24 \\
$0.5 \mathrm{P}-\mathrm{H}$ & 3.48 \\
$0.5 \mathrm{P}-2 \mathrm{H}$ & 3.46 \\
$0.5 \mathrm{P}-3 \mathrm{H}$ & 3.48 \\
$0.2 \mathrm{P}-\mathrm{Ar}$ & 3.25 \\
$0.2 \mathrm{P}-\mathrm{H}$ & 3.47 \\
$0.2 \mathrm{P}-2 \mathrm{H}$ & 3.50 \\
$0.2 \mathrm{P}-3 \mathrm{H}$ & 3.50 \\
\hline
\end{tabular}

growth and selective etching effect not only makes the film surface smooth but also leads to small grain, corresponding to the results in Figures 3, 5, and 6. The effects of hydrogen on the morphology of $\mathrm{ZnS}$ films were similar to those of a-Si:H, $\mu \mathrm{c}-$ $\mathrm{Si}: \mathrm{H}$, or c-Si:H. But further study such as molecular dynamics simulations, infrared spectroscopy, and other means may be put into use to have a better understanding in this respect.

3.4. Optical and Electrical Properties. The optical transmittance spectra of $\mathrm{ZnS}$ thin films in the wavelength range of 300 to $500 \mathrm{~nm}$ are shown in Figure 7. It shows an obvious difference in the absorption edge of films with and without hydrogen and little difference between 0.5 and $0.2 \mathrm{~Pa}$. The absorption edge of samples with hydrogen is about $30 \mathrm{~nm}$ short wavelength shift compared with those without hydrogen.

Table 2 lists the optical band gap $\left(E_{g}\right)$ of the above $\mathrm{ZnS}$ films. The optical band gaps were calculated from the following expression by assuming a direct transition between valance and conduction bands:

$$
(\alpha h \nu)^{2}=D\left(h \nu-E_{g}\right),
$$

where $D$ is a constant, $h$ is Planck's constant, and $\alpha$ is the optical absorption coefficient. $E_{g}$ can be estimated by extrapolating the straight-line portion of the spectrum to a zero absorption coefficient value. In Table 2, the band gaps of the films in pure Ar are $3.24 \mathrm{eV}$ and $3.25 \mathrm{eV}$, respectively. The band gaps of the films in $\mathrm{Ar}+\mathrm{H}_{2}$ are all about $3.48 \mathrm{eV}$. It means that the existence of hydrogen had a big influence on the optical band gaps of $\mathrm{ZnS}$ films grown by RF magnetron sputtering. But it seems that the amount of hydrogen has not made obvious influence on the band gap of films.

The resistivity of all $\mathrm{ZnS}$ films was measured to be in the magnitude of $10^{5} \sim 10^{6} \Omega \cdot \mathrm{cm}$ and the conduction type could not be obtained by thermal probe test system.

\section{Conclusions}

Zinc sulfide thin films were deposited at different atmosphere and pressures. The films show wurtzite polycrystalline structure with (111) preferred orientation. It is observed that relatively lower sputtering pressure at $0.2 \mathrm{~Pa}$ leads to larger grain size and higher deposition rate of the $\mathrm{ZnS}$ thin films. Hydrogen plays a very important role in the deposition of 
ZnS films and would lead to better crystallinity and larger crystallite size and band gap of the films. The band gaps of the films in $\mathrm{Ar}+\mathrm{H}_{2}$ are around $3.48 \mathrm{eV}$. It is also demonstrated that hydrogen can result in a better stoichiometric composition of the films. The resistivity of $\mathrm{ZnS}$ films prepared was high about $10^{5 \sim 6} \Omega \cdot \mathrm{cm}$.

\section{Conflict of Interests}

The authors declare that there is no conflict of interests regarding the publication of this paper.

\section{Acknowledgments}

The research is supported by the National Program on Key Basic Research Project (973 Program) (no. 2011CBA00708) and Key Scientific and Technological Project of Sichuan Province (no. 2011GZ0015).

\section{References}

[1] S. W. Shin, S. R. Kang, K. V. Gurav et al., "A study on the improved growth rate and morphology of chemically deposited ZnS thin film buffer layer for thin film solar cells in acidic medium," Solar Energy, vol. 85, no. 11, pp. 2903-2911, 2011.

[2] N. D. Kumar, M. P. Joshi, C. S. Friend, P. N. Prasad, and R. Burzynski, "Organic-inorganic heterojunction light emitting diodes based on poly(p-phenylene vinylene)/cadmium sulfide thin films," Applied Physics Letters, vol. 71, no. 10, pp. 1388-1390, 1997.

[3] R. Sathyamoorthy, S. Chandramohan, P. Sudhagar, D. Kanjilal, D. Kabiraj, and K. Asokan, "Structural and photoluminescence properties of swift heavy ion irradiated CdS thin films," Solar Energy Materials and Solar Cells, vol. 90, no. 15, pp. 2297-2304, 2006.

[4] L.-X. Shao, K.-H. Chang, and H.-L. Hwang, "Zinc sulfide thin films deposited by RF reactive sputtering for photovoltaic applications," Applied Surface Science, vol. 212-213, pp. 305-310, 2003.

[5] E. Y. M. Lee, N. H. Tran, and R. N. Lamb, "Growth of ZnS films by chemical vapor deposition of $\mathrm{Zn}\left[\mathrm{S}_{2} \mathrm{CN}\left(\mathrm{CH}_{3}\right)_{2}\right]_{2}$ precursor," Applied Surface Science, vol. 241, no. 3-4, pp. 493-496, 2005.

[6] A. Ichiboshi, M. Hongo, T. Akamine, T. Dobashi, and T. Nakada, "Ultrasonic chemical bath deposition of $\mathrm{ZnS}(\mathrm{O}, \mathrm{OH})$ buffer layers and its application to CIGS thin-film solar cells," Solar Energy Materials and Solar Cells, vol. 90, no. 18-19, pp. 31303135, 2006.

[7] P. Roy, J. R. Ota, and S. K. Srivastava, "Crystalline ZnS thin films by chemical bath deposition method and its characterization," Thin Solid Films, vol. 515, no. 4, pp. 1912-1917, 2006.

[8] N. Fathy and M. Ichimura, "Photoelectrical properties of $\mathrm{ZnS}$ thin films deposited from aqueous solution using pulsed electrochemical deposition," Solar Energy Materials and Solar Cells, vol. 87, no. 1-4, pp. 747-756, 2005.

[9] S. Yano, R. Schroeder, B. Ullrich, and H. Sakai, "Absorption and photocurrent properties of thin ZnS films formed by pulsedlaser deposition on quartz," Thin Solid Films, vol. 423, no. 2, pp. 273-276, 2003.

[10] D. H. Hwang, J. H. Ahn, K. N. Hui, K. S. Hui, and Y. G. Son, "Structural and optical properties of $\mathrm{ZnS}$ thin films deposited by RF magnetron sputtering," Nanoscale Research Letters, vol. 7, article 26, pp. 1-13, 2012.

[11] K. Zhang, F. Zhu, C. H. A. Huan, and A. T. S. Wee, "Effect of hydrogen partial pressure on optoelectronic properties of indium tin oxide thin films deposited by radio frequency magnetron sputtering method," Journal of Applied Physics, vol. 86, no. 2, pp. 974-980, 1999.

[12] V. Klykov, I. Strazdina, and V. Kozlov, "Influence of hydrogen content and sputtering characteristics on the properties of $\mathrm{ZnO}: \mathrm{Al}$ transparent conductive layers deposited on polymer substrate," Surface and Coatings Technology, vol. 211, pp. 180183, 2012.

[13] W. F. Liu, G. T. Du, Y. F. Sun et al., "Effects of hydrogen flux on the properties of Al-doped $\mathrm{ZnO}$ films sputtered in $\mathrm{Ar}+\mathrm{H}_{2}$ ambient at low temperature," Applied Surface Science, vol. 253, no. 6, pp. 2999-3003, 2007.

[14] G. Zhang, P. Yan, Z. Wu, J. Wang, and J. Chen, “The effect of hydrogen on copper nitride thin films deposited by magnetron sputtering," Applied Surface Science, vol. 254, no. 16, pp. 50125015,2008

[15] J.-L. Chung, J.-C. Chen, and C.-J. Tseng, "Preparation of $\mathrm{TiO}_{2}$ doped $\mathrm{ZnO}$ films by radio frequency magnetron sputtering in ambient hydrogen-argon gas," Applied Surface Science, vol. 255, no. 5, pp. 2494-2499, 2008.

[16] Y. Wang, X. Zhang, Q. Huang, C. Wei, and Y. Zhao, "Room temperature deposition of highly conductive and transparent hydrogen and tungsten co-doped $\mathrm{ZnO}$ films for thin film solar cells applications," Solar Energy Materials and Solar Cells, vol. 110, pp. 94-97, 2013.

[17] M. V. Ponomarev, K. Sharma, M. A. Verheijen, M. C. M. van de Sanden, and M. Creatore, "Improved conductivity of aluminum-doped $\mathrm{ZnO}$ : the effect of hydrogen diffusion from a hydrogenated amorphous silicon capping layer," Journal of Applied Physics, vol. 111, no. 6, Article ID 063715, 2012.

[18] M. J. Kushner, "A model for the discharge kinetics and plasma chemistry during plasma enhanced chemical vapor deposition of amorphous silicon," Journal of Applied Physics, vol. 63, no. 8, pp. 2532-2551, 1988.

[19] B. Tuttle and J. B. Adams, "Energetics of hydrogen in amorphous silicon: an ab initio study," Physical Review B-Condensed Matter and Materials Physics, vol. 57, no. 20, pp. 12859-12868, 1998.

[20] S. Sriraman, S. Agarwal, E. S. Aydil, and D. Maroudas, "Mechanism of hydrogen-induced crystallization of amorphous silicon," Nature, vol. 418, no. 6893, pp. 62-65, 2002.

[21] S. Sriraman, M. S. Valipa, E. S. Aydil, and D. Maroudas, "Hydrogen-induced crystallization of amorphous silicon thin films. I. Simulation and analysis of film postgrowth treatment with H2 plasmas," Journal of Applied Physics, vol. 100, no. 5, Article ID 053514, 2006.

[22] K. Saitoh, M. Kondo, M. Fukawa et al., "Role of the hydrogen plasma treatment in layer-by-layer deposition of microcrystalline silicon," Applied Physics Letters, vol. 71, no. 23, pp. 34033405, 1997. 

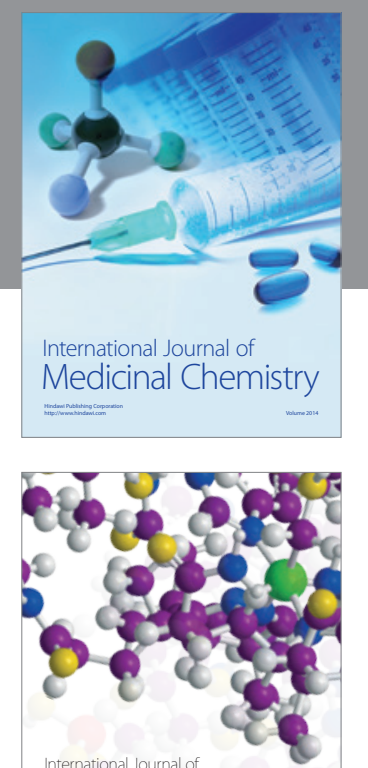

\section{Carbohydrate} Chemistry

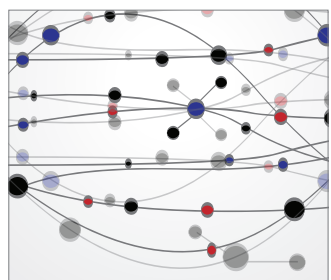

The Scientific World Journal
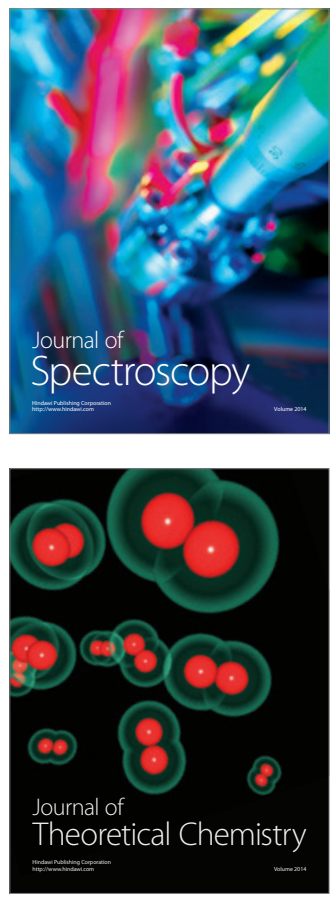
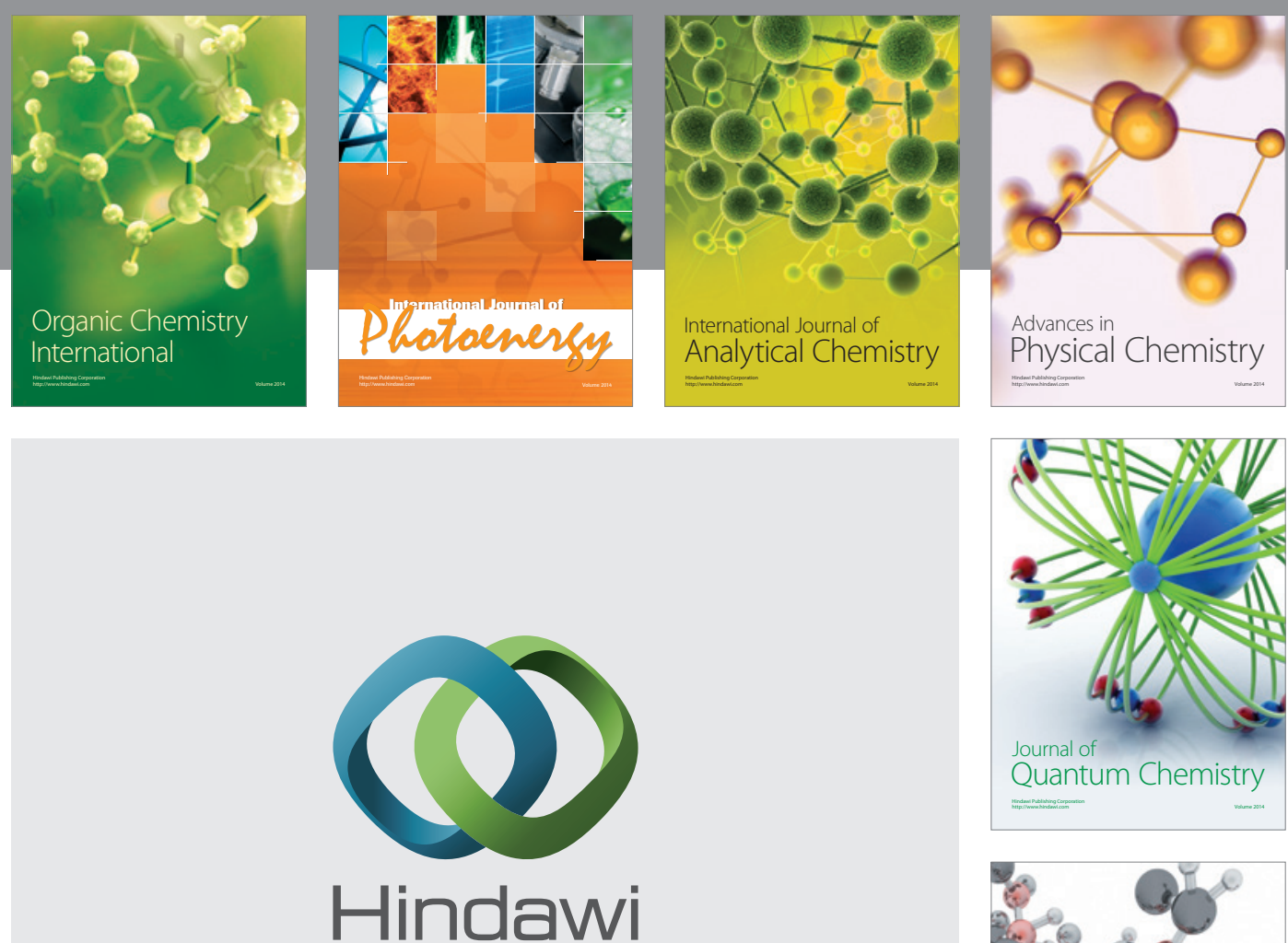

Submit your manuscripts at

http://www.hindawi.com

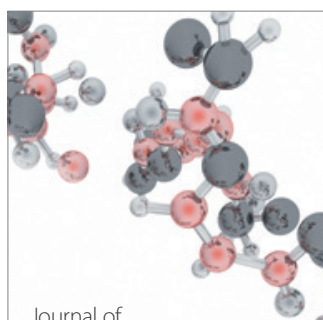

Analytical Methods

in Chemistry

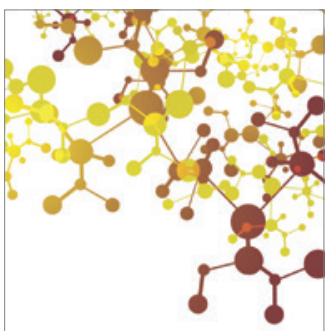

Journal of

Applied Chemistry

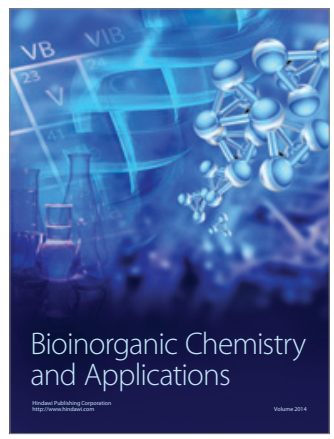

Inorganic Chemistry
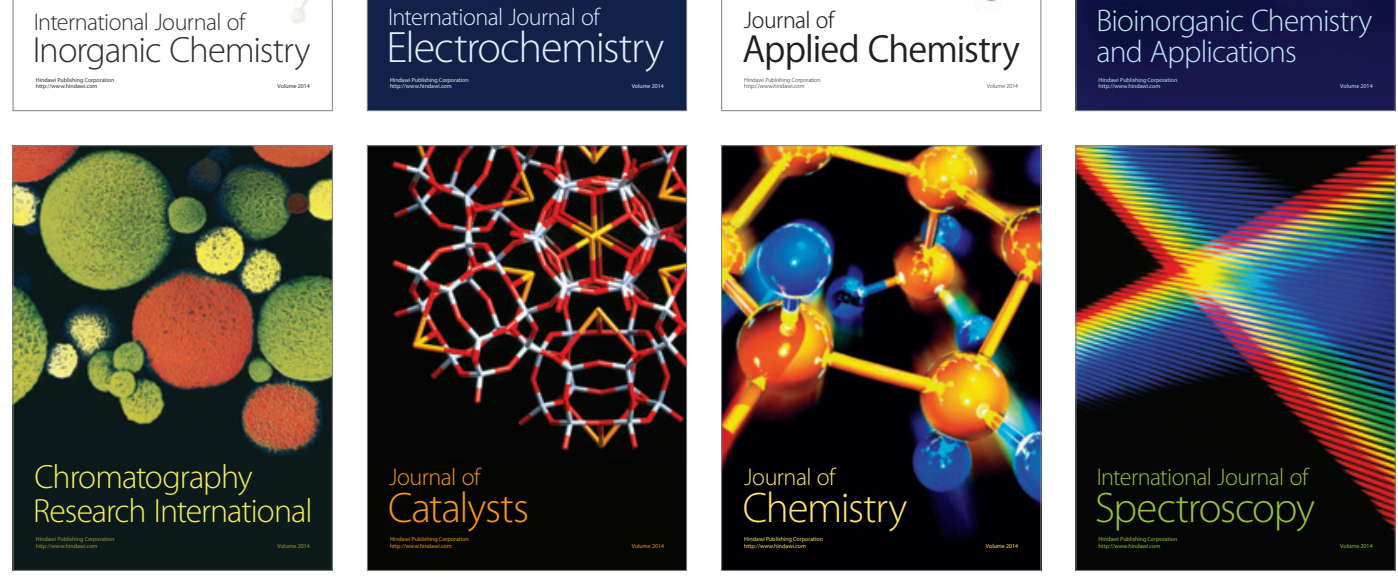